\title{
Chance or challenge, spoilt for choice? New recommendations on diagnostic and therapeutic considerations in hereditary transthyretin amyloidosis with polyneuropathy: the German/Austrian position and review of the literature
}

\author{
Maike F. Dohrn ${ }^{1}$ - Michaela Auer-Grumbach ${ }^{2} \cdot$ Ralf Baron $^{3}$ - Frank Birklein ${ }^{4} \cdot$ Fabiola Escolano-Lozano ${ }^{4}$ \\ Christian Geber $^{5} \cdot$ Nicolai Grether $^{6} \cdot$ Tim Hagenacker $^{7} \cdot$ Ernst Hund $^{8,9} \cdot$ Juliane Sachau $^{3}$. Matthias Schilling ${ }^{10}$. \\ Jens Schmidt ${ }^{11}$. Wilhelm Schulte-Mattler ${ }^{12}$. Claudia Sommer ${ }^{13} \cdot$ Markus Weiler $^{8,9} \cdot$ Gilbert Wunderlich $^{6,14}$. \\ Katrin Hahn ${ }^{15}$
}

Received: 7 May 2020 / Revised: 27 May 2020 / Accepted: 29 May 2020 / Published online: 4 June 2020

(c) The Author(s) 2020

\begin{abstract}
Hereditary transthyretin amyloidosis is caused by pathogenic variants $\left(\mathrm{ATTR}_{\mathrm{v}}\right)$ in the $T T R$ gene. Alongside cardiac dysfunction, the disease typically manifests with a severely progressive sensorimotor and autonomic polyneuropathy. Three different drugs, tafamidis, patisiran, and inotersen, are approved in several countries, including the European Union and the United States of America. By stabilizing the TTR protein or degrading its mRNA, all types of treatment aim at preventing amyloid deposition and stopping the otherwise fatal course. Therefore, it is of utmost importance to recognize both onset and progression of neuropathy as early as possible. To establish recommendations for diagnostic and therapeutic procedures in the follow-up of both pre-symptomatic mutation carriers and patients with manifest $\mathrm{ATTR}_{\mathrm{v}}$ amyloidosis with polyneuropathy, German and Austrian experts elaborated a harmonized position. This paper is further based on a systematic review of the literature. Potential challenges in the early recognition of disease onset and progression are the clinical heterogeneity and the subjectivity of sensory and autonomic symptoms. Progression cannot be defined by a single test or score alone but has to be evaluated considering various disease aspects and their dynamics over time. The first-line therapy should be chosen based on individual symptom constellations and contra-indications. If symptoms worsen, this should promptly implicate to consider optimizing treatment. Due to the rareness and variability of $\mathrm{ATTR}_{\mathrm{v}}$ amyloidosis, the clinical course is most importantly directive in doubtful cases. Therefore, a systematic follow-up at an experienced center is crucial to identify progression and reassure patients and carriers.
\end{abstract}

Keywords TTR amyloidosis · Diagnostic intervals · Follow-up monitoring · Pre-symptomatic carriers · TTR stabilizers · Gene-silencing therapies

\section{Introduction}

Hereditary transthyretin amyloidosis was first described by the Portuguese neurologist Andrade in 1952 [1]. Based on the typical symptoms at onset, he named the disease "mal

Electronic supplementary material The online version of this article (https://doi.org/10.1007/s00415-020-09962-6) contains supplementary material, which is available to authorized users.

Maike F. Dohrn

mdohrn@ukaachen.de

Extended author information available on the last page of the article dos pézinhos" (painful feet). In 1978, Costa and colleagues identified abnormal prealbumin, which is identical with transthyretin (TTR), to be part of the amyloid deposits [2]. Both wild-type $\left(\mathrm{ATTR}_{\mathrm{wt}}\right)$ and mutant variants $\left(\mathrm{ATTR}_{\mathrm{v}}\right)$ of TTR amyloid can cause a systemic amyloidosis.

$\mathrm{ATTR}_{\mathrm{v}}$ amyloidosis is a rare, hereditary disease of autosomal dominant inheritance typically manifesting with a rapidly progressive sensorimotor and autonomic polyneuropathy, but also causing cardiac dysfunction, ocular, and gastrointestinal symptoms [3]. Relying on broad observatory studies of the Portuguese patient population, Coutinho and colleagues classified three disease stages (Fig. 1) based 


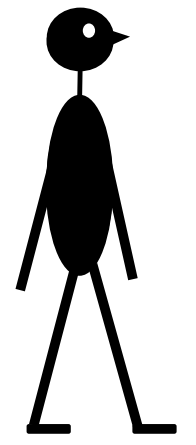

A

Stage 1
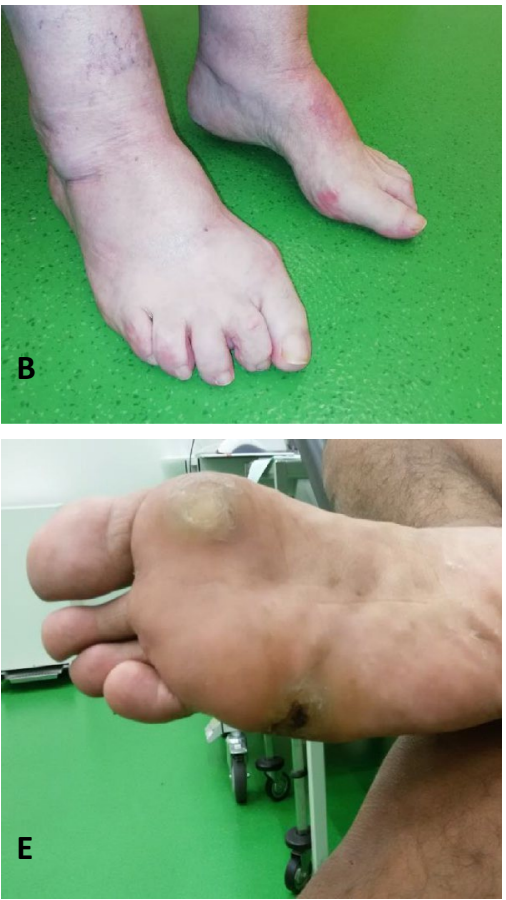

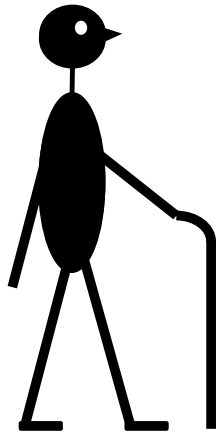

Stage 2
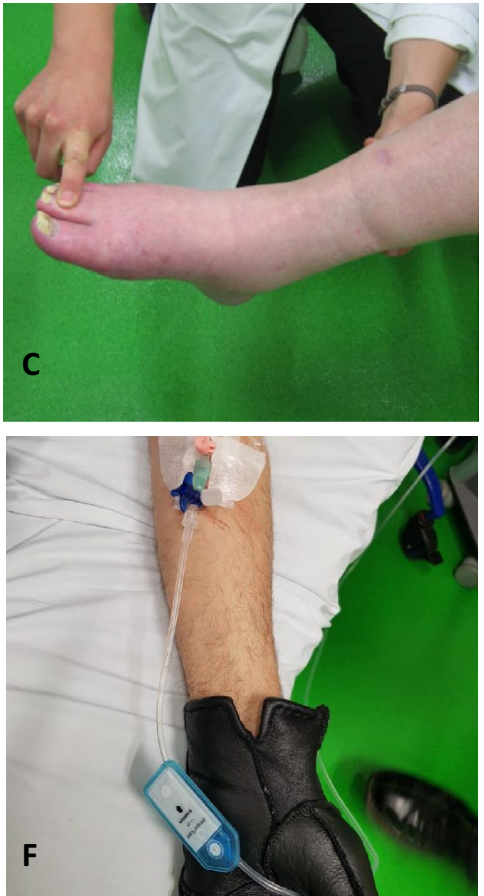

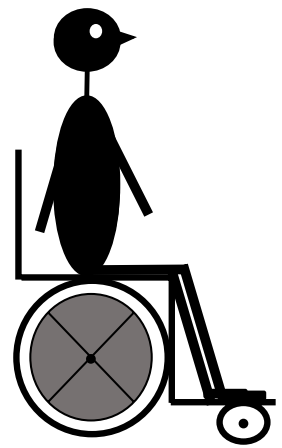

Stage 3
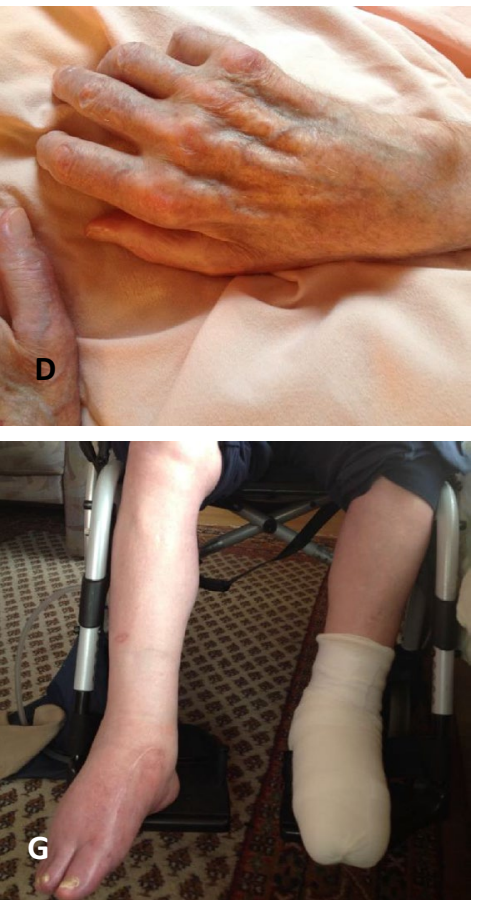

Fig. 1 Coutinho disease stages. The natural course of ATTR $_{\mathrm{v}}$ amyloidosis-related polyneuropathy is traditionally divided into three stages. a A symptomatic patient, who is fully ambulant, is classified as stage 1 . The need of one or two walking aids defines stage 2 . Whenever a patient becomes wheelchair-bound or bedridden, an affected individual will be categorized as a stage 3 patient. The score does not depict cardiac and autonomic symptoms and cannot distinguish between a primarily motor gait disturbance and an afferent ataxia as the lead-

on walking capacity [4]: a symptomatic, but fully ambulatory patient is therefore in stage 1 , the need for walking aids defines stage 2, and wheelchair dependence stage 3 . To underline its systemic disease character, the international society of amyloidosis (ISA) replaced the previous disease name "familial amyloidotic polyneuropathy" (FAP) by the term "ATTR ${ }_{\mathrm{v}}$ amyloidosis" in 2018 [5], in which "v" stands for variant and can be specified by the respective mutation. Depending on the leading manifestation, "with ing cause for ambulatory impairment. b A stage 1 patient with ankle edema and claw toes. c A stage 2 patient with weakness of toe elevation and ankle edema. d A bedridden stage 3 patient with advanced atrophies of the intrinsic hand muscles. e A stage 1 patient with nonhealing wounds and previous toe amputations. f A stage 2 patient, who wears gloves to prevent painful skin contact. $\mathrm{g}$ The same patient as in C 2 years later: Wheelchair-bound, ankle edema, and non-healing wounds

polyneuropathy" can optionally be added to refine this diagnosis.

More than 140 mutations in the TTR gene have been described to date, most of which are amyloidogenic [6]. By destabilizing the TTR tetramer, a circulating transport protein of thyroxine and retinol binding protein, some mutations foster its dissociation, the rate-limiting step of amyloidogenesis, while others facilitate misfolding and denaturation of monomers and therefore the irreversible 
formation of amyloid fibrils. Besides the already deposited amyloid fibrils, non-fibrillar circulating formations contribute to neurotoxicity and organ dysfunction [7, 8]. Comparing endemic and non-endemic areas, the clinical course varies distinctly even within carriers of the same TTR mutation [3, 9-11]. With an arbitrary cut-off at the age of 50 years, the typical early-onset and the mostly non-endemic late-onset type of disease are distinguished. The pathophysiological background of this phenotypic spectrum has not been fully understood to date. Depending on the regional (and individual) penetrance, some mutation carriers only develop first symptoms at the age of 70 years or older, whereas others remain asymptomatic within their entire life span. Indicators of an underlying $\operatorname{ATTR}_{\mathrm{v}}$ amyloidosis are both a rapidly progressive sensory or sensorimotor neuropathy typically accompanied by autonomic dysfunction and cardiac and/or gastrointestinal symptoms $[12,13]$. To confirm the diagnosis, a pathogenic mutation must be proven by TTR sequencing [14]. In Germany and Austria, amyloid deposits can, but do not necessarily have to be shown in tissue specimens, such as abdominal fat aspirates, salivary glands, myocardial biopsies, sural nerve, or skin specimens. Some patients are identified by occasional amyloid findings in tissue biopsies of other indication.

If untreated, the combination of heart failure, wasting, and secondary infections leads to death within 7-11 years after onset [15]. As more than $90 \%$ of circulating TTR is of hepatic origin, the first ever causative treatment option was liver transplant, which has successfully been conducted since 1990 [16, 17]. The replacement of mutant by wild-type TTR therefore constitutes the first form of genetic therapy, which significantly improved the patients' life expectancy [17-20]. Based on the high risk of age- and stage-related complications, however, liver transplantation is not recommended in elderly patients and in those with an advanced disease stage or cardiac involvement. For younger patients as well, the procedures associated with the surgery and a life-long immunosuppression entail a high health burden. Besides, it is now known that the ATTR $_{\mathrm{v}}$-related symptoms can secondarily progress after liver transplant, which is due to seeding effects of previously deposited amyloid [21]. In a dosage of $20 \mathrm{mg}$ per day, the TTR-stabilizing oral drug tafamidis meglumine has received its approval in the European Union (EU) for the treatment of stage 1 ATTR $_{\mathrm{v}}$ polyneuropathy in 2011. In several clinical trials, it showed to significantly slow down neurological and cardiological aspects of the disease course [22-24], which led to approval by the federal drug and food administration (FDA) for ATTR cardiomyopathy in a higher dosage of $60 \mathrm{mg}$ in 2019. In 2018 , two novel treatment approaches, the small interfering RNA patisiran [25] and the antisense oligonucleotide inotersen [26], were both approved in the EU and USA for the first and second disease stages of $\mathrm{ATTR}_{\mathrm{v}}$ amyloidosis with polyneuropathy. Based on the highly specific degradation of TTR messenger RNA (mRNA) in hepatocytes, the serum TTR levels were significantly reduced by both drugs. Compared with placebo-treated patients, this resulted in a highly significant benefit concerning neuropathy progression and quality of life.

With the availability of causative treatment options (Table 1) that all aim at stopping or slowing down disease progression, it is of greatest importance to recognize ATTR ${ }_{v}$ amyloidosis as early as possible. Due to the rarity of the disease and frequent misdiagnoses in the first place, however, therapy can be fatally prolonged.

In this work, a group of German and Austrian neurologists experienced in the treatment of $\mathrm{ATTR}_{\mathrm{v}}$ amyloidosis has joined their expertise and summarized the following comprehensive recommendations.

\section{Methodologies}

The present work summarizes the current literature and the authors' recommendations on diagnostic and therapeutic procedures in the neurological work-up of $\mathrm{ATTR}_{\mathrm{v}}$ amyloidosis. Compiling the neurological consensus position of the German and Austrian interdisciplinary amyloidosis centers, it represents the non-endemic areas, in which $\mathrm{ATTR}_{\mathrm{v}}$ is a very rare and often overseen disease. Located at 12 different centers, the authors currently treat approximately 250 patients in stage 1 or stage 2 with one of the approved drugs and further provide follow-up and care for about 100 stage 3 patients and 100 stage 0 mutation carriers. Additionally, they follow about 600 patients with ATTR $_{\mathrm{wt}}$ amyloidosis. Previous recommendations [27] have been implemented.

\section{Disease relevance}

\section{Epidemiology}

$\operatorname{ATTR}_{\mathrm{v}}$ amyloidosis is considered a rare, an "orphan" disease. With known cases in more than 30 countries all over the globe [28], the local disease frequency is highly variable. "Endemic" areas with a particularly high prevalence are defined regions in northern Portugal and Sweden, where one in 1000-10,000 inhabitants would contract the disease [15].

In Germany and Austria, there are about 400 known disease cases to date [14]; however, several patients and families might be undiagnosed so far. The estimated prevalence varies from 1 to 5 cases in 1 million inhabitants [15, 28].

The most prevalent mutation worldwide is the exchange of the amino acid methionine for valine at protein position 50 (Val30Met following the traditional TTR classification; 
Table 1 Approved medications

\begin{tabular}{|c|c|c|c|}
\hline & Tafamidis (Vyndaqel ${ }^{\mathrm{TM}}$ ) & Patisiran (Onpattro ${ }^{\mathrm{TM}}$ ) & Inotersen $\left(\right.$ Tegsedi $\left.{ }^{\mathrm{TM}}\right)$ \\
\hline Countries with approval & $\begin{array}{l}\text { European Union, Iceland, Norway, } \\
\text { Liechtenstein, Japan, Argentina, } \\
\text { Mexico, Israel, South Korea, } \\
\text { Brazil, Hong Kong, Macau, } \\
\text { Macedonia, Russia, Colom- } \\
\text { bia, Serbia, United States of } \\
\text { America, United Arab Emirates, } \\
\text { Australia, Canada, Singapore, } \\
\text { Switzerland }\end{array}$ & $\begin{array}{l}\text { European Union, Switzerland, } \\
\text { United States of America, } \\
\text { Canada, Brazil, Japan }\end{array}$ & $\begin{array}{l}\text { European Union, United States of } \\
\text { America, Canada, Brazil }\end{array}$ \\
\hline Approved in Europe since & 2011 & 2018 & 2018 \\
\hline $\begin{array}{l}\text { Approval limited to Coutinho } \\
\text { stage }\end{array}$ & 1, cardiomyopathy & 1 and 2 & 1 and 2 \\
\hline Application & Oral & i.v. & s.c. \\
\hline Frequency & $1 \times /$ day & $1 \times / 3$ weeks & $1 \times /$ week \\
\hline Pre-medication & None & $\begin{array}{l}\text { Paracetamol, prednisolone, H1- } \\
\text { and H2-receptor blockers }\end{array}$ & None \\
\hline Endpoints of phase III trial & $\begin{array}{l}\text { Stabilization of NIS-LL and qual- } \\
\text { ity of life }\end{array}$ & $\begin{array}{l}\text { TTR knockdown by } \sim 80 \% \text {, } \\
\text { improvement of mNIS }+7 \text {, and } \\
\text { quality of life }\end{array}$ & $\begin{array}{l}\text { TTR knockdown by } \sim 70 \% \text {, } \\
\text { stabilization of } \mathrm{mNIS}+7 \text {, and } \\
\text { quality of life }\end{array}$ \\
\hline Long-term data & $\sim 70 \%$ response rate & No data & No data \\
\hline $\begin{array}{l}\text { Significant effect on cardiomyo- } \\
\text { pathy }\end{array}$ & Yes & Yes & Yes \\
\hline Blood-brain barrier passage & Partial & None & None \\
\hline Severe side effects & None & Infusion reactions & $\begin{array}{l}6 \text { SAEs in the phase III trial: } 3 \times \\
\text { thrombopenia, } 3 \times \text { glomerulo- } \\
\text { nephritis }\end{array}$ \\
\hline
\end{tabular}

Synoptic summary on the three drugs tafamidis, patisiran, and inotersen all approved in Europe and the United States of America. The herein depicted data have been retrieved from the respective specialist information and all three phase III trials [22, 25, 26]

i.v. intravenous, s.c. subcutaneous, $H 1 / H 2$ histamine receptors, $N I S-L L$ neuropathy impairment score for lower limbs, $m N I S+7$ modified neuropathy impairment score with seven additional items, $S A E$ serious adverse event

c.148G >A; p.Val50Met following the Human Gene Mutation Database), which accounts for about $99 \%$ of the Portuguese and $95 \%$ of the Swedish cases [15, 29]. In non-endemic countries, such as Germany, Austria, and Switzerland, ATTR p.Val50Met $_{\text {amyloidosis causes about } 40-60 \%}$ of all cases relating to a greater genetic heterogeneity with more than 20 other known pathogenic variants [15]. Genotype-phenotype correlations provide a broad spectrum of disease manifestations partially correlating with the underlying variant. Some mutations (e.g., p.Val40Ile, p.Val142Ile) are preponderantly associated with a cardiomyopathy, whereas others (p.Val50Met) typically manifest with a leading neuropathy. The p.Leu75Pro variant is known to cause a particularly rapid and aggressive course $[8,30]$, while the two benign variants p.Arg124His and p.Thr139Met have a TTR-stabilizing effect even in compound heterozygosity with p.Val50Met, reducing fibril deposition and causing a milder clinical picture [31]. One genetic variant can, however, cause different onset phenotypes, and even within the same families, the symptom spectrum can be heterogeneous.
Underlying genetic and external disease modifiers are not yet fully understood and merit further investigation.

Up to $25 \%$ of the elderly population ( 80 years and beyond) are estimated to have systemic amyloid deposits caused by wild-type TTR (ATTR ${ }_{w t}$ ) known for its amyloidogenicity even though not associated with mutations in the TTR gene [32]. In ATTR $_{\mathrm{wt}}$ amyloidosis, a probably still underdiagnosed disease in the elderly population, the clinical picture is typically dominated by a cardiomyopathy, the symptomatic impact of which ranges from asymptomatic to congestive heart failure. Men are more frequently affected than women. The presence and pattern of an associated polyneuropathy have so far not been systemically investigated in ATTR $_{\mathrm{wt}}$ amyloidosis. With its consequences for patient mobility, however, it merits further investigation and a cautious screening in clinical practice.

\section{Stages, scales, and scores}

With recent upcoming treatment options, the classification of disease stages and the definition of progression have 
gained greater clinical relevance (Fig. 1). It is recommended that disease dynamics should be evaluated by trained and, if possible, always the same neurologists. A detailed overview on the relevant examinations and score validations for clinical practice is given in Table 3 and in the Supplementary Material.

Following Coutinho and colleagues [4], four stages (0-3) are commonly applied focusing on the patient's ambulatory capacity with or without aids (Fig. 1). Accordingly, the Peripheral Neuropathy Disability (PND) score [33] consists of five stages, which sub-differentiate walking ability in more detail (e.g., one or two crutches required). Both scores focus on gait and only partially depict motor and sensory qualities, which can be somewhat unprecise in practice, for example, no difference is made between afferent ataxia or steppage as the leading cause of instability. Small fiber-associated sensory and autonomic symptoms are under-represented. In close correlation with the detailed neurological status, the Neuropathy Impairment Score (NIS) [34] comprises a range of 0-244 points depicting isolated muscle strength, deep tendon reflexes, and a distal qualitative sensory assessment. For a more extensive, but also more objective assessment of each patient's status, the NIS score has further been developed now (mNIS+7), including quantitative sensory testing (QST), nerve conduction studies (NCS), and autonomic test results. In the phase III APOLLO [25] and NEURO-TTR [26] study protocols, the mNIS+7 score was used with slight modifications concerning test parameters and sum score values. Based on these protocols, it is therefore not possible to carry out head-to-head comparisons of the two trials or trial drugs.

In real-life practice beyond the clinical trials, it is important to know not only the defining marks but also the typical overall patterns of symptom development within the treatment-limiting Coutinho stages: asymptomatic mutation carriers, identified by predictive genetic testing, are classified as Coutinho stage 0 . For these pre-symptomatic individuals, there is no treatment approved. The symptomatic stage 1 commonly manifests with painful dysesthesias, numbness, and/or a reduction of temperature and pain perception in feet, while the walking ability is still independent from aids. As thinly or unmyelinated small nerve fibers are most prone to early damage in ATTR $_{\mathrm{v}}$ amyloidosis, muscle strength and deep tendon reflexes are typically preserved in the very early stage 1 ; however, autonomic symptoms can already be present. With disease progression, sensory symptoms rise up to the lower legs and hands. Neuropathic pain is typically described as a burning sensation with worsening at night. The loss of proprioception and pallesthesia as well as progressive weakness initially affecting toe extensors, but rapidly involving lower legs and hands, indicate a large fiber involvement in the disease course. Disturbed wound healing can lead to severe painless ulcerations up to osteomyelitis and the need of amputations. Due to afferent ataxia, steppage, and orthostatic dysregulation, gait disturbances might require the need of walking aids. This is what defines the brink to stage 2 . When a patient becomes wheelchair-bound or bedridden, stage 3 is reached meaning that all of the currently available treatment options are no longer approved.

Besides sensorimotor impairment, autonomic symptoms essentially contribute to the disease burden, which is, however, not stage defining. Especially in early-onset patients, symptoms such as early satiety, diarrhea, and unintended weight loss, incontinence, erectile dysfunction, disturbed sweating, and orthostatic intolerance can be the predominant or even first manifestations of the disease potentially causing life-threatening complications such as urogenital infections, cardiac arrhythmia, and wasting [27]. In terms of cardiac involvement, $80 \%$ of all $\mathrm{ATTR}_{\mathrm{v}}$ patients develop an increased myocardial wall thickness leading to restrictive cardiomyopathy and cardiac conduction disturbances including arrhythmia. Severe ocular manifestations like vitreous opacities and trabecular obstruction affect about $5-10 \%$ of the patients in the first disease stage but become more prevalent over time [35, 36]. Renal impairment with proteinuria and/or a reduced glomerular filtration can additionally occur in the advanced disease course. When gastrointestinal mucosae are affected by amyloid deposition, this can contribute to disturbed resorption of nutrients additionally to the effects of autonomic neuropathy. In the sum, all of this can cause severe muscular atrophy, wasting, and an increased liability to infections $[3,10]$.

\section{Treatment options}

$\mathrm{ATTR}_{\mathrm{v}}$ amyloidosis is a progressive, disabling disease with a lethal course if untreated. This has not only been consistently confirmed by several studies on the natural disease course, but also by prospective data obtained from the placebo groups of several clinical trials [25, 26]. Optimizing both span and quality of life must therefore be the major goal for all diagnostic and therapeutic considerations on a causative and symptomatic level.

Treating a systemic disease further requires an overall interdisciplinary work-up in both diagnostic and therapeutic procedures. Expert boards including cardiologists, hematologists, gastroenterologists, ophthalmologists, genetic counselors, and neurologists, mostly located at the specialized centers, engage the assignment of optimizing individual treatment strategies.

Stopping disease progression is the key intention of causative treatment, including TTR stabilization and knockdown. In the presence of contraindications or if a disease stage has already been reached that is too advanced for approved causative treatment options, this aim switches towards a 
best possible symptom control, including management of pain, ulcerations, infections, diarrhea, dyspnea, depression, and anxiety. Despite the sparse data availability [37], physiotherapy and rehabilitation are considered to be beneficial for patients suffering from $\mathrm{ATTR}_{\mathrm{v}}$ amyloidosis with polyneuropathy as it has been shown for other hereditary neuropathies, such as Charcot-Marie-Tooth disease [38]. Physiotherapy is intended to maintain or improve strength and walking ability, to delay osteoarticular complications, and to preserve activities of daily living. Furthermore, an individually tailored orthosis treatment is mandatory. As part of a multidisciplinary rehabilitative approach, social medicine aspects should also be included.

An absolute requirement for the initiation of any causative treatment for stage 1 or 2 neuropathy is a pathogenic $T T R$ mutation proven by genetic testing. For asymptomatic mutation carriers or patients, who are no longer ambulant, there is currently no approved treatment available. Other than in countries such as Portugal, the detection of amyloid in a tissue biopsy is not considered obligatory in Germany and Austria. A discontinuous distribution of amyloid deposits might lead to false-negative histopathological results, so that waiting for a positive biopsy result can even delay an early intervention. Performing biopsies is recommended, whenever the cause of neuropathy symptoms is unclear especially in the presence of differential diagnoses such as diabetes or alcohol consumption as well as "refractory" chronic inflammatory demyelinating polyneuropathy (CIDP), which is one of the most frequent misdiagnoses of $\mathrm{ATTR}_{\mathrm{v}}$ amyloidosis $[39,40]$.

In the EU, USA, and other countries including Canada and Brazil, there are currently three drugs approved for the treatment of the $\mathrm{ATTR}_{\mathrm{v}}$-related polyneuropathy (Table 1).

\section{TTR stabilization: tafamidis meglumine and diflunisal}

The small molecule tafamidis meglumine (Vyndaqe ${ }^{\mathrm{TM}}$ ), an orally applicable benzoxazole, selectively binds human plasma TTR in the thyroxine binding groove, which has a stabilizing effect on the tetramer. By creating a kinetic barrier for tetramer dissociation, the rate-limiting step of amyloidogenesis, tafamidis intervenes in the early steps of pathophysiology [22, 41, 42]. In the EU, the approval for the $20 \mathrm{mg}$ dosage became effective in 2011; however, it has so far been limited to the first Coutinho stage of ATTR $\mathrm{v}$-related polyneuropathy meaning that patients need to be fully ambulatory without aids. In an 18-month lasting phase III trial, the intended stop of progression was realized in $60 \%$ of the treated compared to $38 \%$ of the placebo group [22]. Additionally, the modified body mass index (mBMI) and quality of life both showed a tendency towards stabilization under treatment, while continuously worsening in controls
$[22,43]$. An open-label extension trial with a time span of 5.5 years confirmed these data in a cohort of 71 patients [44]. The neurological outcome was measured by the neuropathy impairment score for lower limbs (NIS-LL), which turned out to increase significantly less in the verum compared with the placebo group. Accordingly, the nutritional status and quality of life were significantly better in the tafamidis group. Another trial showed a significant benefit in a smaller cohort of non-p.Val50Met patients as well [45]. The first long-term data on tafamidis in $\mathrm{ATTR}_{\mathrm{v}}$-neuropathy patients revealed a negative correlation between the symptom severity at the beginning of treatment and the treatment response, pointing towards the necessity of an early diagnosis [23]. In October 2018, a new trial was published examining the 30-month effect of tafamidis in different dosages on the TTR-related cardiomyopathy including both hereditary and wild-type-associated forms of cardiac amyloidosis [24]. Primary outcome parameters were the overall survival and the reduction of cardiovascular events leading to hospitalization, secondary ones the clinical (6-min walk test) and functional (echocardiography, laboratory parameters) performance all being met from the 18-month visit on [24]. Tafamidis was well tolerated in all trials with a very low rate of side effects, such as vomiting or urinary tract infections. Since Mai 2019, tafamidis is approved in the USA for the treatment of both ATTR $_{\mathrm{v}}$ - and $\mathrm{ATTR}_{\mathrm{wt}}$-related cardiomyopathy, and in February 2020, the indication was accordingly broadened in Europe for the higher daily dosage of $60 \mathrm{mg}$.

Another medication with a stabilizing effect on the TTR tetramer is the non-steroidal antiphlogistic drug diflunisal, which structurally resembles tafamidis. A randomized, placebo-controlled trial including 130 patients with ATTR $\checkmark$ amyloidosis revealed in 2013 that diflunisal treatment can significantly reduce the NIS +7 score comparing the verum and placebo group over a time span of 2 years. A stabilization of neuropathy symptoms was reached in $29 \%$ of the verum and in $9 \%$ of the placebo group [46]. Due to its nephro- and cardiotoxic side effects and potential interactions with anticoagulant drugs, however, diflunisal has not been approved in Germany and Austria to date.

\section{Translational modification}

By sequence-specific degradation of mRNA, gene-silencing therapies impede the translation of the intended target protein. This mechanism is independent from the underlying mutation inhibiting the overall hepatic production of the TTR protein. The drug has to be transferred to hepatocytes, where and where only it is meant to evolve its mRNA degrading effect. There are currently two gene-silencing drugs approved in the EU and USA for the treatment of polyneuropathy in $\mathrm{ATTR}_{\mathrm{v}}$ amyloidosis, which differ in the way of reaching hepatocytes and the specific process of mRNA 
degradation, but both have a reduction of circulating TTR protein as their common effect mechanism.

\section{Patisiran}

The mechanism of patisiran (Onpattro ${ }^{\mathrm{TM}}$ ) is based on RNA interference (RNAi), which naturally happens in eukaryotic cells as part of the antiviral defense [47]. Patisiran consists of double-stranded oligonucleotides sized 21 base pairs in a lipid nanoparticle (LNP) formulation. It specifically recognizes and binds the complementary mRNA at the $3^{\prime}$ ending of the TTR gene, therefore inducing the so-called RNA-induced silencing complex (RISC). One of the major challenges is to deliver the substance to the target site, where it can then leap into action. To be selectively admitted to hepatocytes [48] and not to be destroyed by nucleases on the way, patisiran uses the aforementioned LNP layer, which fuses with endosomal membranes and therefore releases the oligonucleotides into cytoplasm.

In the APOLLO trial [25], an 18-month lasting, randomized, placebo-controlled phase III study with 225 participants, an intravenous application of $0.3 \mathrm{mg}$ of patisiran per kg body weight every 3 weeks led to an $81 \%$ reduction (mean) of serum TTR. The primary endpoint, a stabilization of the mNIS+7 neuropathy score, was fully met. While placebo-treated patients worsened in a range of $28 \pm 2.6$ points, the verum cohort actually showed a clinical improvement with a point development of $-6 \pm 1$ points, which was statistically significant compared to both placebo and baseline. As most important secondary endpoint, the patients' quality of life was accordingly improved [25]. Subgroup analyses additionally revealed an improvement of structural and functional cardiac markers (left ventricular hypertrophy, global longitudinal strain, $\mathrm{N}$-terminal pro brain natriuretic peptide, and $10 \mathrm{~m}$ walk test) pointing out towards a positive effect of patisiran treatment on the ATTR $_{\mathrm{v}}$-related cardiomyopathy as well [49]. The most frequent side effects included peripheral edema and infusion reactions. In total, there were 13 deaths reported in the APOLLO trial, which were equally distributed in the placebo and the verum group and did not relate to the drug, but to the severity of the underlying disease itself.

In August 2018, patisiran received its approval in the EU and in the USA for the treatment of ATTR ${ }_{\mathrm{v}}$-related polyneuropathy in Coutinho stages 1 and 2. The application is intravenous in a weight-dependent dosage of $0.3 \mathrm{mg} / \mathrm{kg}$ every 3 weeks. The infusion runs for about $80 \mathrm{~min}$ and requires a pre-medication with dexamethasone, paracetamol, and a combined $\mathrm{H} 1 / \mathrm{H} 2$ receptor blockade. As the suppression of circulating TTR protein comes along with reduced vitamin A levels, a daily substitution is recommended in an oral dosage of 2500 IE. Home nursing programs have recently become available in some countries including Germany.

\section{Inotersen}

Inotersen (Tegsedi ${ }^{\mathrm{TM}}$ ) is a short, single-stranded, synthetic nucleic acid in a saline formulation, which selectively binds the TTR mRNA in the nucleus of hepatocytes and therefore activates the cell's own RNases for degradation. Antisense oligonucleotides (ASOs) constitute a novel, but clinically yet established therapeutic concept for regulating protein expression and limiting toxic gain-of-function effects.

In the international phase III NEURO-TTR trial, 172 patients with stage 1 or $2 \mathrm{ATTR}_{\mathrm{v}}$-related polyneuropathy received inotersen or placebo in a 2:1 randomization. TTR serum levels were effectively reduced to about $25 \%$ (mean) of the baseline. Compared to placebo, the verum group showed a significantly lower mNIS +7 score and a significantly better quality of life in the Norfolk QoL score at week 66 . These results were independent from the exact mutation, the Coutinho stage, and the presence or absence of cardiomyopathy [26]. Patients, who had previously been treated with tafamidis or diflunisal also showed a significant benefit from inotersen treatment. Focusing on the ATTR ${ }^{\mathrm{v}}$-related cardiomyopathy, subgroup analyses showed a significant reduction of the left ventricular volume and septum diameter [50].

The most common side effects were nausea and vomiting, fever, glomerulonephritis, and alterations in the peripheral blood count. A relevant reduction of platelets occurred in about $60 \%$ of all inotersen-treated patients. One patient deceased due to intracranial hemorrhage associated with severe thrombopenia below $10 / \mathrm{nl}$. It is therefore obligatory to monitor both blood cell counts and renal function on a regular basis (for details view expert information). It is further recommended to substitute vitamin A in a dosage of 2500 IE daily.

In July 2018, the EMA and FDA both approved inotersen for stage 1 and 2 ATTR $_{\mathrm{v}}$-related polyneuropathy. The application is subcutaneous in a weekly dosage of $284 \mathrm{mg}$. There is no pre-medication required.

\section{Choice of medication}

Which of all available treatment options might be the best to begin with is an individual decision that has to be made on the basis of comorbidities and risk profiles. In stage 1 of neuropathy, all three medications come into question, while only patisiran and inotersen are approved for stage 2 . It is not appropriate to maintain the first chosen drug until the brink of stage 2 comes to sight. To evaluate the need for and 
response to treatment, it is crucial to monitor the individual patient's symptoms, to measure progression, and to recognize the earliest possible moment for switching therapeutic modalities [27].

In case of disease progression under therapy, it is necessary to consider changing the treatment modality as soon as possible. How exactly these switching algorithms look like, however, is a question that has so far not been addressed in the literature nor substantiated by trial data. If tafamidis is the first-line therapy of choice, either patisiran or inotersen should be chosen by individual risk constellations and patient's preference. No scientific data support or refute the possibility that a patient progressive under one translation modification drug might respond to the other. It therefore remains an individual decision whether and how to switch in such case. Mechanistically, it appears not very likely that a patient progressive under RNA degradation treatment will respond to TTR stabilizers; however, the literature does not exclude this option neither. Halting one treatment due to side effects, might, however, be a different situation. If, for example, a stage 1 patient can no longer take patisiran or inotersen, this individual might still profit from tafamidis treatment.

\section{Diagnostic standards and follow-up monitoring}

Standardized, interdisciplinary follow-up programs at experienced, networking centers are required to adequately address the heterogeneous penetrance and genotype-phenotype variations in terms of age at onset and organ involvement. These programs have to be sensitive enough on the one hand to assess the broad variety of disease manifestations, but on the other hand, they have to be dynamic and practicable for both patients and physicians. Local routines might, notwithstanding, be influenced by the endemic mutation spectrum $[15,51,52]$. Harmonizing the experience of the German and Austrian centers, it is recommended to monitor progression not focusing on one particular score only, but by repeatedly using a broad clinical approach, including a detailed patient history, clinical examinations, quantitative sensory testing (especially in the early disease phase), NCS (becomes representative within the course of stage 1), examinations of autonomic function (can be disturbed in the early course already), and specific questionnaires on autonomic disturbances, neuropathic pain, disability, and quality of life. A detailed overview on the recommended examinations is given in table 3 and in the supplementary material (Table 3 ).

Independent from the therapy of choice, it is always necessary to start as early as possible to prevent an irreversible nerve damage [53] and to achieve the best conceivable treatment response [25, 26, 44, 54]. The point of symptom onset should therefore be the time of treatment onset as well.

\section{Follow-up intervals}

\section{Asymptomatic mutation carriers}

Due to the high variability in penetrance, a person with a positive predictive gene test result cannot be considered a "patient", but an "individual at risk". A clear distinction between pre-symptomatic "carriers" and symptomatic "patients" has therefore become a major diagnostic challenge. On the one hand, immediate recognition of the first signs of disease onset enables early intervention, which is essential for the patient's prognosis. On the other hand, an important aim of follow-up procedures is to reassure individuals at risk typically having been closely involved in their relatives' fatal disease course, by taking on the responsibility for symptom monitoring [55]. Depending on the underlying TTR mutation and the onset age in other affected family members, the predicted age at disease onset (PADO) might help estimate a carrier's symptom onset as well [53]. It is recommended in the recent literature to start monitoring such an individual at risk about 10 years prior to PADO [53]. This can, however, be adapted to the intrafamilial variability and to the carrier's personal demand.

As progression is one of the strongest red flag signs for disease onset in $\mathrm{ATTR}_{\mathrm{v}}$ amyloidosis in order to distinguish from unspecific symptoms potentially related to other conditions or even to an increased introspection, it is helpful to dispose of long-term follow-up data gathered at one experienced center. It is herein recommended to schedule a detailed clinical follow-up at least once yearly (Table 2). A mutation carrier is considered symptomatic if subjectively reported complaints, including autonomic disturbances, sensory deficits, and/or neuropathic pain, come together with at least one objectifiable clinical or paraclinical test result, which is plausibly associated with $\mathrm{ATTR}_{\mathrm{v}}$ amyloidosis [14]. Other "doubtful" constellations, such as asymptomatic carriers with carpal tunnel syndrome or potential neuropathy signs in NCS, merit tighter clinical monitoring. In case of differential diagnosis such as concomitant diabetes mellitus as well, a rapidly progressive disease course is the most relevant indicator of actual $\mathrm{ATTR}_{\mathrm{v}}$ amyloidosis onset, which, again, requires regular follow-up examinations, for example, every three months.

\section{Symptomatic patients}

After beginning or switching treatment, it is recommended to monitor $\mathrm{ATTR}_{\mathrm{v}}$ amyloidosis patients in three-month 
Table 2 Recommended intervals for different types of visits and examinations

\begin{tabular}{llllll}
\hline Coutinho stage & 0 & 1 & 2 & 3 & $\begin{array}{c}\text { After change } \\
\text { in medication }\end{array}$ \\
\hline
\end{tabular}

Patient history (recommended intervals in months)

$\begin{array}{llllll}\text { Sensorimotor symptoms } & (6-) 12 & 6(-12) & (3-) 6 & (3-) 12 & 3 \\ \text { Autonomic symptoms } & (6-) 12 & 6(-12) & (3-) 6 & (3-) 12 & 3 \\ \text { Medication } & (6-) 12 & 6(-12) & (3-) 6 & (3-) 12 & 3\end{array}$

Neurological examination (recommended intervals in months)

$\begin{array}{llllll}\text { Qualitative sensory status } & (6-) 12 & 6(-12) & (3-) 6 & (6-) 12 & 3 \\ \text { Distal muscle strength } & (6-) 12 & 6(-12) & (3-) 6 & (6-) 12 & 3 \\ \text { Gait stability } & (6-) 12 & 6(-12) & (3-) 6 & (6-) 12 & 3 \\ \text { Deep tendon reflexes } & (6-) 12 & 6(-12) & (3-) 6 & (6-) 12 & 3\end{array}$

Paraclinical examinations (recommended intervals in months)

$\begin{array}{llllll}\text { Nerve conduction studies } & 12(-24) & 6(-12) & 6 & - & 6 \\ \text { Quantitative sensory testing } & (6-) 12 & 6(-12) & (6) & - & 6 \\ \text { Skin conductance tests } & (6-) 12 & 6(-12) & (6) & - & 6 \\ \text { Schellong's test } & (6-) 12 & 6(-12) & 6 & - & 3\end{array}$

Clinical scores and questionnaires (recommended intervals in months)

$\begin{array}{llllll}\text { NIS } & 12 & 6(-12) & (3-) 6 & (6-) 12 & 3 \\ \text { PND/Coutinho stages } & 12 & 6(-12) & (3-) 6 & (6-) 12 & 3 \\ \text { COMPASS-31 } & 12 & 6(-12) & (3-) 6 & (6-) 12 & 3 \\ \text { R-ODS } & - & 6(-12) & 6 & (6-) 12 & 6 \\ \text { Norfolk QoL } & - & 6(-12) & 6 & (6-) 12 & 6\end{array}$

Summarized recommendations for examination intervals in the different disease stages. Pre-symptomatic carriers should at least be monitored once per year depending on the physician's discretion and their own preference. Symptomatic patients are recommended to be seen every 6 months. With a growing disease burden, patients in stage 2 might need a tighter follow-up even, whereas with the loss of mobility, stage 3 patients might prefer not to come to the center more often than once per year. Independent from the disease stage, any shift in treatment modalities always requires a tight follow-up at least every 3 months until the disease progression is halted. Representing the first symptoms in an early stage 1 , sensory and autonomic tests are of special interest, while nerve conduction studies can still be normal. With disease progression, however, quantitative sensory testing loses its specificity intervals. The focus of follow-up should be not only on the tolerability of the respective therapy, potential side effects, and the patient's compliance, but also on the favored treatment response meaning a stabilization of symptom progression. Patients being stable under treatment should then undergo regular follow-up visits every 6 months in Coutinho stage 1 and every 3-6 months in Coutinho stage 2, at the treating neurologist's discretion (Table 2). Any worsening of disease symptoms requires immediate changes in the diagnostic and therapeutic procedures: In cases of doubtful progression, it is recommended to increase the frequency of follow-up visits in order to better understand disease dynamics. If a patient is measurably progressive, however, a change in the therapeutic regimen has to be considered. It is neither necessary nor recommended to wait for a change in disease stage before adapting treatment, but to do so as soon as progression can be detected. As autonomic and cardiac symptoms are not fully depicted by the NIS score and its variants, by a change of which progression was defined in several clinical trials $[22,25,26]$, the decision to switch the treatment modality does not necessarily require a pre-defined change in score points, but has to be evaluated based on the individual patient's clinical course.

From a neurological point of view, the pedestal of every diagnostic work-up (Table 3) contains a detailed patient history, a clinical examination including the different modalities of the NIS score, questionnaires (e.g., R-ODS, COMPASS-31, and Norfolk Quality of Life), as well as NCS. If available, examinations, such as quantitative sensory testing (QST), Sudoscan, and sympathetic skin response (SSR), might contribute helpful additional information on small fiber impairment in the very early stage 1 , when NCS are still insensitive. In advanced stages, a detailed clinical examination (NIS) might be sufficient if selectively added by NCS [56, 57]. As a systemic progression marker, the mBMI is easy to assess by multiplying the patient's BMI with the current albumin level $[\mathrm{g} / \mathrm{l}]$ in serum. By doing so, the nutritional status can be controlled and a potential bias caused by cardiac decompensation and peripheral edema is meanwhile addressed.

Based on individual needs, the exchange of information and counseling plays an important role in the diagnostic and 


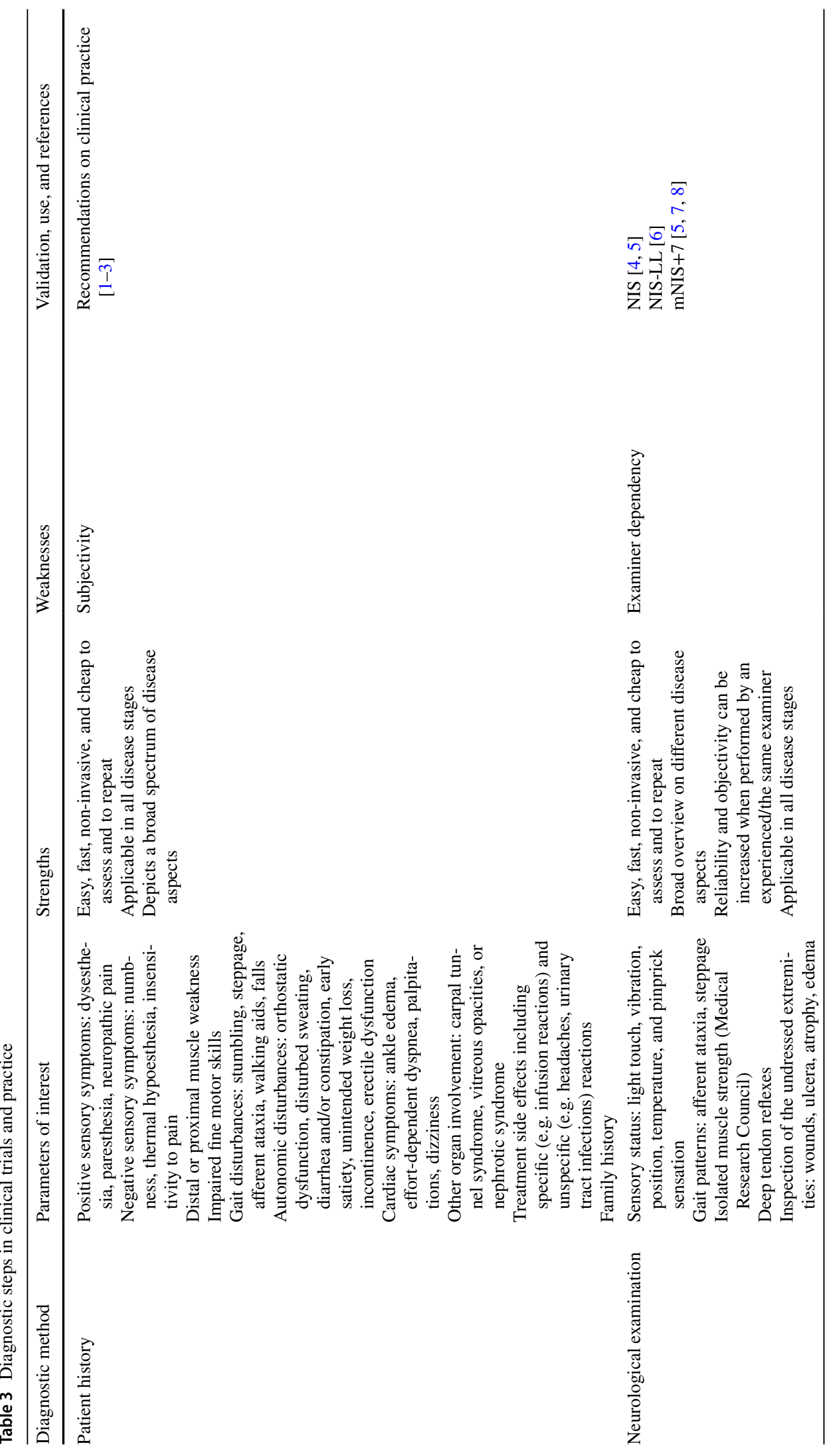




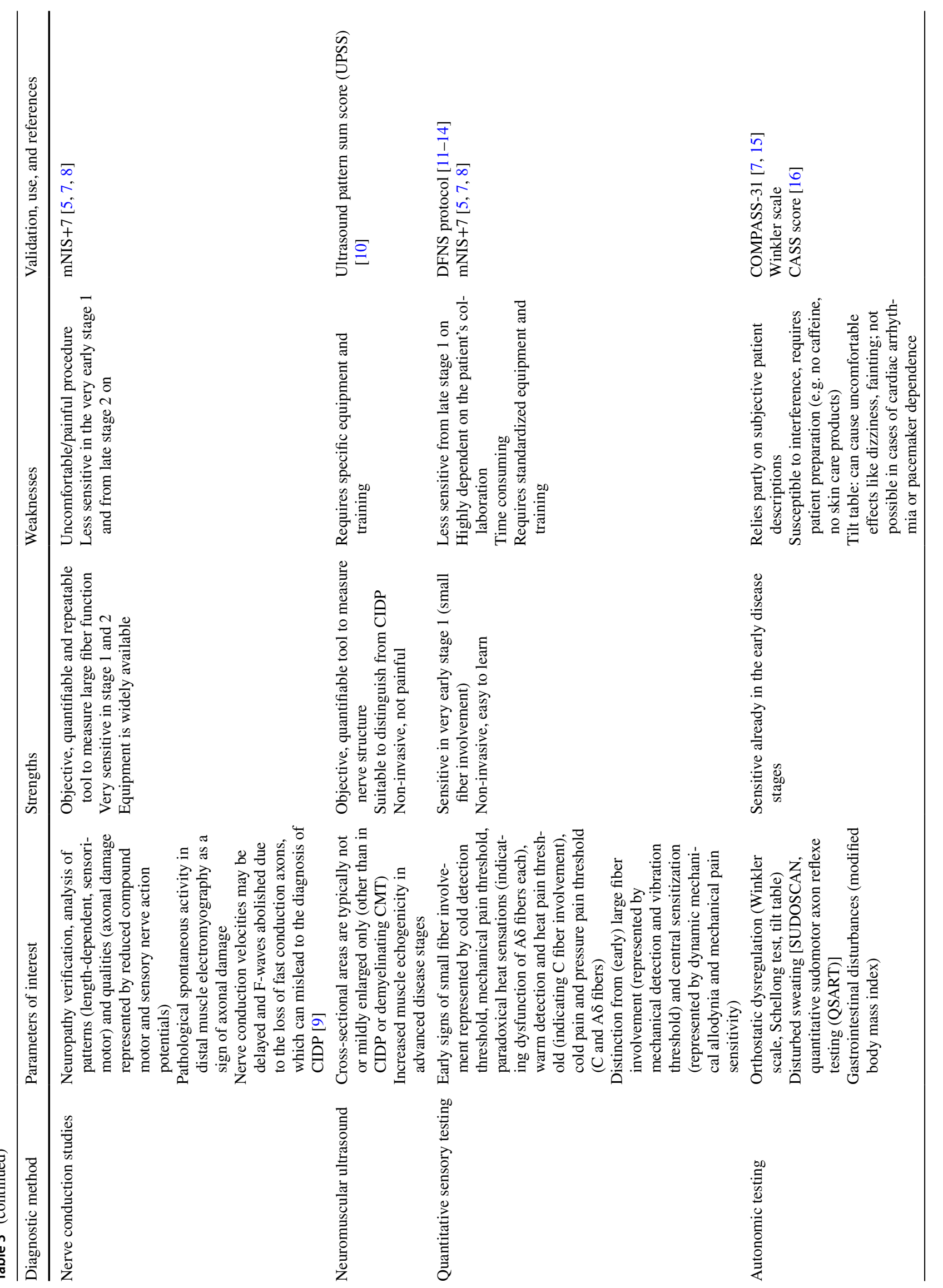




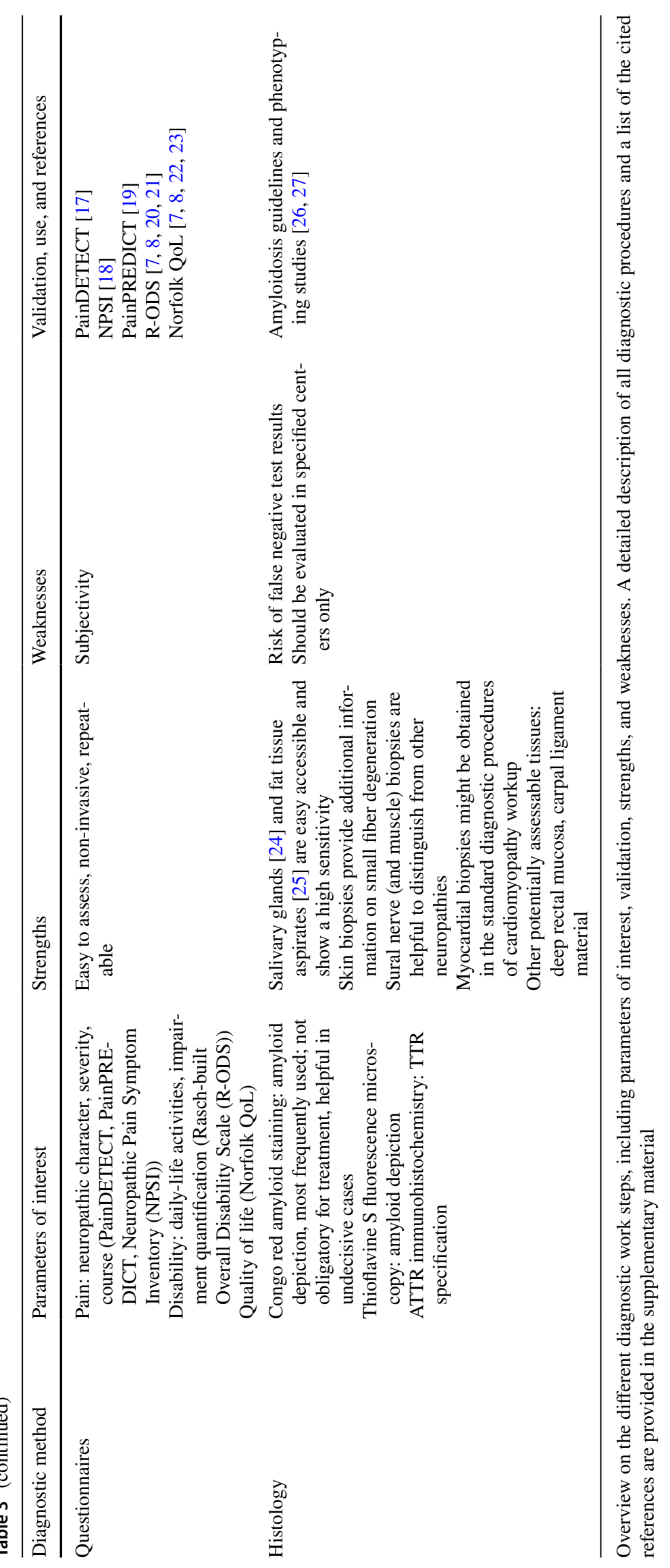


follow-up procedures in patients with $\mathrm{ATTR}_{\mathrm{v}}$ amyloidosis and relatives both being potential caregivers and individuals at risk. It is somewhat challenging and requires extra time to educate, but not to frighten both patients and carriers. An inadequate emotional repression or lack of knowledge might delay the recognition of disease onset, while an exceeding self-observation triggers psychosomatic symptoms potentially disguising $\mathrm{ATTR}_{\mathrm{v}}$ amyloidosis-related complaints as well. Particularly in larger kindreds with long pedigrees of yet deceased antecedents, it is helpful to involve a human geneticist or psychologist experienced in the counseling of fatal diseases.

It is recommended to regularly examine, treat, and counsel all carriers, patients, and caregivers at a local specialized center. These centers are due to forming networks on a national and international basis enabling the low-threshold exchange of knowledge and the participation in clinical trials.

\section{Summary}

Hereditary transthyretin $\left(\mathrm{ATTR}_{\mathrm{v}}\right)$ amyloidosis is a rare, autosomal dominant disease with a progressively disabling and fatal course if untreated. Besides the invasive liver transplantation, three highly specific causative treatment options based on either protein stabilization or mRNA degradation have been approved so far.

In this work, a group of German and Austrian neurologists elaborated their harmonized recommendations for the diagnostic and therapeutic work-up for both pre-symptomatic mutation carriers and symptomatic patients with $\mathrm{ATTR}_{\mathrm{v}}$ amyloidosis-related polyneuropathy.

The overall aim of any causative and symptomatic treatment is the best possible control of disease symptoms. Therefore, it is crucial to start a medication as early as possible. This requires an early recognition of disease onset and a tight monitoring of treatment response. The first-line medication should be chosen individually depending on the respective patient's needs and contra-indications. In case of disease progression under therapy, the treatment modality should be optimized with the least possible delay. Progression, however, cannot be defined by one score or classification but has to be determined by experienced physicians considering both patient-reported symptoms, clinical signs, and measurable test results. Being a systemic disease, however, $\operatorname{ATTR}_{v}$ amyloidosis merits an interdisciplinary approach with regular follow-up visits at an experienced center.

Acknowledgements Open Access funding provided by Projekt DEAL. MFD would like to express her gratitude to Professor Teresa Coelho at the Corino Andrade Unit at the St. António Hospital in Porto, Portugal, for research mentoring and clinical training.
Author contributions MFD and KH have conceptualized and written the first draft of the manuscript. All co-authors have equally contributed through critical review and re-phrasing.

Funding This work did not receive any funding.

\section{Compliance with ethical standards}

Conflicts of interest MFD, FB, FEL, CG, NG, EH, MS, JSch, WSM, $\mathrm{CS}, \mathrm{MW}, \mathrm{GW}$, and $\mathrm{KH}$ received financial reimbursement for consulting and advisory board activities and/or travel support by Akcea, Alnylam, and Pfizer. MFD further received research funding by Pfizer (ASPIRE 2018) and is currently receiving a scholarship for a research fellowship by the German Research Foundation (Deutsche Forschungsgemeinschaft, DFG). RB reports grants/research support from Pfizer Pharma $\mathrm{GmbH}$, Genzyme $\mathrm{GmbH}$, Grünenthal $\mathrm{GmbH}$, Mundipharma Research GmbH und Co. KG., Novartis Pharma GmbH, Alnylam Pharmaceuticals Inc. and Zambon GmbH and as part of the EU Project: "Europain" (115007), the DOLORisk project (633491), the IMI Paincare (777500), the German Federal Ministry of Education and Research (BMBF): Verbundprojekt: Frühdetektion von Schmerzchronifizierung (NoChro) (13GW0338C), and German Research Network on Neuropathic Pain (01EM0903). He has received speaker fees from Pfizer Pharma GmbH, Genzyme GmbH, Grünenthal GmbH, Mundipharma, Sanofi Pasteur, Medtronic Inc. Neuromodulation, Eisai Co.Ltd., Lilly GmbH, Boehringer Ingelheim Pharma GmbH \& Co. KG, Astellas Pharma GmbH, Desitin Arzneimittel GmbH, Teva $\mathrm{GmbH}$, Bayer-Schering, MSD GmbH, Seqirus Australia Pty. Ltd, Novartis Pharma GmbH, TAD Pharma GmbH, Grünenthal SA Portugal, Sanofi-Aventis Deutschland GmbH, Agentur Brigitte Süss, Grünenthal Pharma AG Schweiz, and Grünenthal B.V. Niederlande. He has also been a consultant for Pfizer Pharma GmbH, Genzyme GmbH, Grünenthal GmbH, Mundipharma Research GmbH und Co. KG, Allergan, Sanofi Pasteur, Medtronic, Eisai, Lilly GmbH, Boehringer Ingelheim Pharma GmbH\&Co.KG, Astellas Pharma GmbH, Novartis Pharma GmbH, Bristol-Myers Squibb, Biogenidec, AstraZeneca GmbH, Merck, Abbvie, Daiichi Sankyo, Glenmark Pharmaceuticals S.A., Seqirus Australia Pty. Ltd, Teva Pharmaceuticals Europe Niederlande, Teva GmbH, Genentech, Mundipharma International Ltd. UK, Astellas Pharma Ltd. UK, Galapagos NV, Kyowa Kirin GmbH, Vertex Pharmaceuticals Inc., Biotest AG, Celgene GmbH, Desitin Arzneimittel GmbH, Regeneron Pharmaceuticals Inc. USA, Theranexus DSV CEA Frankreich, Abbott Products Operations AG Schweiz, Bayer AG, Grünenthal Pharma AG Schweiz, Mundipharma Research Ltd. UK, Akcea Therapeutics Germany GmbH, Asahi Kasei Pharma Corporation, AbbVie Deutschland GmbH \& Co. KG, Air Liquide Sante International Frankreich, Alnylam Germany GmbH, Lateral Pharma Pty Ltd, Hexal AG, Ethos Srl Italien, and Janssen. TH and MAG report research support from speaker honoraria from Pfizer, adboard and speaker honoraria from Akcea Therapeutics, adboard, speaker honoraria and research support from Biogen, Sanofi-Genzyme and Roche, adboard and speaker honoraria from CSL Behring and Novartis. JS reports personal fees from Grünenthal $\mathrm{GmbH}$ and travel support from Alnylam Pharmaceuticals Inc. and Pfizer.

Open Access This article is licensed under a Creative Commons Attribution 4.0 International License, which permits use, sharing, adaptation, distribution and reproduction in any medium or format, as long as you give appropriate credit to the original author(s) and the source, provide a link to the Creative Commons licence, and indicate if changes were made. The images or other third party material in this article are included in the article's Creative Commons licence, unless indicated otherwise in a credit line to the material. If material is not included in the article's Creative Commons licence and your intended use is not 
permitted by statutory regulation or exceeds the permitted use, you will need to obtain permission directly from the copyright holder. To view a copy of this licence, visit http://creativecommons.org/licenses/by/4.0/.

\section{References}

1. Andrade C (1952) A peculiar form of peripheral neuropathy: familiar atypical generalized amyloidosis with special involvement of the peripheral nerves. Brain 75(3):408-427

2. Costa PP, Figueira AS, Bravo FR (1978) Amyloid fibril protein related to prealbumin in familial amyloidotic polyneuropathy. Proc Natl Acad Sci USA 75(9):4499-4503

3. Planté-Bordeneuve V, Said G (2011) Familial amyloid polyneuropathy. Lancet Neurol 10(12):1086-1097

4. Coutinho P, Lázaro Da Silva A, Lopes J, Resende P-EA, Monteiro Da Silva A, Resende L, Moura-da Silva A, de Lima Filho J, Barbosa A (1980) Forty years of experience with type I amyloid neuropathy. Review of 483 cases. Amyloid Amyloidosis 88-98

5. Benson MD, Buxbaum JN, Eisenberg DS, Merlini G, Saraiva MJ, Sekijima Y, Sipe JD, Westermark P (2018) Amyloid nomenclature 2018: recommendations by the International Society of Amyloidosis (ISA) nomenclature committee. Amyloid 25(4):215-219

6. Mutations in hereditary amyloidosis (stand 12.5.2018). http:// amyloidosismutations.com/mut-attr.php. Accessed 5 May 2020

7. Sousa MM, Cardoso I, Fernandes R, Guimaraes A, Saraiva MJ (2001) Deposition of transthyretin in early stages of familial amyloidotic polyneuropathy: evidence for toxicity of nonfibrillar aggregates. Am J Pathol 159(6):1993-2000

8. Sousa MM, Fernandes R, Palha JA, Taboada A, Vieira P, Saraiva MJ (2002) Evidence for early cytotoxic aggregates in transgenic mice for human transthyretin Leu55Pro. Am J Pathol 161(5):1935-1948

9. Koike H, Misu K-i, Ikeda S-i, Ando Y, Nakazato M, Ando E, Yamamoto M, Hattori N, Sobue G (2002) Type I (transthyretin Met30) familial amyloid polyneuropathy in Japan: early-vs lateonset form. Arch Neurol 59(11):1771-1776

10. Conceição I, De Carvalho M (2007) Clinical variability in type I familial amyloid polyneuropathy (Val30Met): comparison between late- and early-onset cases in Portugal. Muscle Nerve 35(1):116-118

11. Hund E, Linke R, Willig F, Grau A (2001) Transthyretin-associated neuropathic amyloidosis: pathogenesis and treatment. Neurology 56(4):431-435

12. Sekijima $Y$, Ueda M, Koike $H$, Misawa $S$, Ishii $T$, Ando $Y$ (2018) Diagnosis and management of transthyretin familial amyloid polyneuropathy in Japan: red-flag symptom clusters and treatment algorithm. Orphanet J Rare Dis 13(1):6

13. Planté-Bordeneuve V, Ferreira A, Lalu T, Zaros C, Lacroix C, Adams D, Said G (2007) Diagnostic pitfalls in sporadic transthyretin familial amyloid polyneuropathy (TTR-FAP). Neurology 69(7):693-698

14. Hund E, Kristen AV, Auer-Grumbach M, Geber C, Birklein F, Schulte-Mattler W, Sommer C, Schmidt H, Röcken C (2018) Transthyretin-amyloidose (ATTR-amyloidose): empfehlungen zum management in Deutschland und Österreich. Aktuelle Neurologie 45(08):605-616

15. Parman Y, Adams D, Obici L, Galán L, Guergueltcheva V, Suhr OB, Coelho T (2016) Sixty years of transthyretin familial amyloid polyneuropathy (TTR-FAP) in Europe: where are we now? A European network approach to defining the epidemiology and management patterns for TTR-FAP. Curr Opin Neurol 29(Suppl 1):S3
16. Holmgren G, Steen L, Ekstedt J, Groth CG, Ericzon BG, Eriksson S, Andersen O, Karlberg I, Nordén G, Nakazato M (1991) Biochemical effect of liver transplantation in two Swedish patients with familial amyloidotic polyneuropathy (FAP-met30). Clin Genet 40(3):242-246

17. Holmgren G, Steen L, Suhr O, Ericzon B-G, Groth C-G, Andersen O, Wallin B, Seymour A, Richardson S, Hawkins P (1993) Clinical improvement and amyloid regression after liver transplantation in hereditary transthyretin amyloidosis. Lancet 341(8853):1113-1116

18. Suhr O, Holmgren G, Steen L, Wikström L, Norden G, Friman S, Duraj FF, Groth CG, Ericzon B (1995) Liver transplantation in familial amyloidotic polyneuropathy. Follow-up of the first 20 Swedish patients. Transplantation 60(9):933-938

19. Benson MD (2013) Liver transplantation and transthyretin amyloidosis. Muscle Nerve 47(2):157-162

20. Yamashita T, Ando Y, Okamoto S, Misumi Y, Hirahara T, Ueda M, Obayashi K, Nakamura M, Jono H, Shono M (2012) Longterm survival after liver transplantation in patients with familial amyloid polyneuropathy. Neurology 78(9):637-643

21. Liepnieks JJ, Zhang LQ, Benson MD (2010) Progression of transthyretin amyloid neuropathy after liver transplantation. Neurology 75(4):324-327

22. Coelho T, Maia LF, da Silva AM, Cruz MW, Planté-Bordeneuve V, Lozeron P, Suhr OB, Campistol JM, Conceição IM, Schmidt HH-JJN (2012) Tafamidis for transthyretin familial amyloid polyneuropathy: a randomized, controlled trial. Neurology 79(8):785-792

23. Planté-Bordeneuve V, Gorram F, Salhi H, Nordine T, Ayache SS, Le Corvoisier P, Azoulay D, Feray C, Damy T, Lefaucheur J-P (2017) Long-term treatment of transthyretin familial amyloid polyneuropathy with tafamidis: a clinical and neurophysiological study. J Neurol 264(2):268-276

24. Maurer MS, Schwartz JH, Gundapaneni B, Elliott PM, Merlini G, Waddington-Cruz M, Kristen AV, Grogan M, Witteles R, Damy T (2018) Tafamidis treatment for patients with transthyretin amyloid cardiomyopathy. N Engl J Med 379(11):1007-1016

25. Adams D, Gonzalez-Duarte A, O'Riordan WD, Yang C-C, Ueda M, Kristen AV, Tournev I, Schmidt HH, Coelho T, Berk JL (2018) Patisiran, an RNAi therapeutic, for hereditary transthyretin amyloidosis. N Engl J Med 379(1):11-21

26. Benson MD, Waddington-Cruz M, Berk JL, Polydefkis M, Dyck PJ, Wang AK, Planté-Bordeneuve V, Barroso FA, Merlini G, Obici L (2018) Inotersen treatment for patients with hereditary transthyretin amyloidosis. N Engl J Med 379(1):22-31

27. Adams D, Ando Y, Beirão JM, Coelho T, Gertz MA, Gillmore JD, Hawkins PN, Lousada I, Suhr OB, Merlini G (2020) Expert consensus recommendations to improve diagnosis of ATTR amyloidosis with polyneuropathy. J Neurol. https://doi.org/10.1007/ s00415-019-09688-0

28. Schmidt HH, Waddington-Cruz M, Botteman MF, Carter JA, Chopra AS, Hopps M, Stewart M, Fallet S, Amass L (2018) Estimating the global prevalence of transthyretin familial amyloid polyneuropathy. Muscle Nerve 57(5):829-837

29. Inês M, Coelho T, Conceição I, Duarte-Ramos F, de Carvalho M, Costa J (2018) Epidemiology of transthyretin familial amyloid polyneuropathy in Portugal: a nationwide study. Neuroepidemiology 51(3-4):177-182

30. Cardoso I, Goldsbury C, Müller S, Olivieri V, Wirtz S, Damas A, Aebi U, Saraiva M (2002) Transthyretin fibrillogenesis entails the assembly of monomers: a molecular model for in vitro assembled transthyretin amyloid-like fibrils. J Mol Biol 317(5):683-695

31. Almeida M, Alves I, Terazaki H, Ando Y, Saraiva M (2000) Comparative studies of two transthyretin variants with protective 
effects on familial amyloidotic polyneuropathy: TTR R104H and TTR T119M. Biochem Biophys Res Commun 270(3):1024-1028

32. Westermark P, Sletten K, Johansson B, Cornwell GG (1990) Fibril in senile systemic amyloidosis is derived from normal transthyretin. Proc Natl Acad Sci USA 87(7):2843-2845

33. Yamamoto S, Wilczek H, Nowak G, Larsson M, Oksanen A, Iwata T, Gjertsen H, Söderdahl G, Wikström L, Ando Y (2007) Liver transplantation for familial amyloidotic polyneuropathy (FAP): a single-center experience over 16 years. Am J Transplant 7(11):2597-2604

34. Dyck PJ, Sherman WR, Hallcher LM, John Service F, O'Brien PC, Grina LA, Palumbo PJ, Swanson CJ (1980) Human diabetic endoneurial sorbitol, fructose, and myo-inositol related to sural nerve morphometry. Ann Neurol 8(6):590-596

35. Beirao JM, Malheiro J, Lemos C, Beirao I, Costa P, Torres P (2015) Ophthalmological manifestations in hereditary transthyretin (ATTR V30M) carriers: a review of 513 cases. Amyloid 22(2):117-122

36. Ando E, Ando Y, Okamura R, Uchino M, Ando M, Negi A (1997) Ocular manifestations of familial amyloidotic polyneuropathy type I: long term follow up. Br J Ophthalmol 81(4):295-298

37. Filipova M, Popova D, Georgieva S, Mihaylova N (2016) Physiotherapy's methods for familial amyloid polyneuropathy. In: Лечебная физическая культура: достижения и перспективы развития: материалы $\mathrm{V}$ Всероссийской научно-практической конференции с международным участием 25-26 мая 2016 г.// Под общей редакцией НЛ Ивановой, ОВ Козыревой.-М.: РГУФКСМиТ, 2016.-318 с.: илл., р 294

38. Corrado B, Ciardi G, Bargigli C (2016) Rehabilitation management of the Charcot-Marie-tooth syndrome: a systematic review of the literature. Medicine (Baltim) 95(17):e3278

39. Mathis S, Magy L, Diallo L, Boukhris S, Vallat JM (2012) Amyloid neuropathy mimicking chronic inflammatory demyelinating polyneuropathy. Muscle Nerve 45(1):26-31

40. Lozeron P, Mariani L-L, Dodet P, Beaudonnet G, Théaudin M, Adam C, Arnulf B, Adams D (2018) Transthyretin amyloid polyneuropathies mimicking a demyelinating polyneuropathy. Neurology 91(2):e143-e152

41. Bulawa CE, Connelly S, DeVit M, Wang L, Weigel C, Fleming JA, Packman J, Powers ET, Wiseman RL, Foss TR (2012) Tafamidis, a potent and selective transthyretin kinetic stabilizer that inhibits the amyloid cascade. Proc Natl Acad Sci USA 109(24):9629-9634

42. Said G, Grippon S, Kirkpatrick P (2012) Tafamidis. Nature Publishing Group, Berlin

43. Coelho T, Maia L, da Silva AM, Waddington M, Plante-Bordeneuve V, Lozeron P, Suhr OB, Campistol J, Conceicao I, Schmidt H (2010) Tafamidis (Fx-1006A): a first-in-class disease-modifying therapy for transthyretin type familial amyloid polyneuropathy. In: Neurology, vol 9. Lippincott Williams \& Wilkins, Philadelphia, pp A286-A286

44. Waddington Cruz M, Amass L, Keohane D, Schwartz J, Li H, Gundapaneni B (2016) Early intervention with tafamidis provides long-term (5.5-year) delay of neurologic progression in transthyretin hereditary amyloid polyneuropathy. Amyloid 23(3):178-183

45. Merlini G, Planté-Bordeneuve V, Judge DP, Schmidt H, Obici L, Perlini S, Packman J, Tripp T, Grogan DR (2013) Effects of tafamidis on transthyretin stabilization and clinical outcomes in patients with non-Val30Met transthyretin amyloidosis. J Cardiovasc Transl Res 6(6):1011-1020

46. Berk JL, Suhr OB, Obici L, Sekijima Y, Zeldenrust SR, Yamashita T, Heneghan MA, Gorevic PD, Litchy WJ, Wiesman JF (2013) Repurposing diflunisal for familial amyloid polyneuropathy: a randomized clinical trial. JAMA 310(24):2658-2667

47. Coelho T, Adams D, Silva A, Lozeron P, Hawkins PN, Mant T, Perez J, Chiesa J, Warrington S, Tranter E (2013) Safety and efficacy of RNAi therapy for transthyretin amyloidosis. N Engl J Med 369(9):819-829

48. Zhao Y, Huang L (2014) Lipid nanoparticles for gene delivery. In: Advances in genetics, vol 88. Elsevier, Amsterdam, pp 13-36

49. Solomon SD, Adams D, Kristen A, Grogan M, González-Duarte A, Maurer MS, Merlini G, Damy T, Slama MS, Brannagan TH III (2019) Effects of patisiran, an RNA interference therapeutic, on cardiac parameters in patients with hereditary transthyretinmediated amyloidosis: analysis of the APOLLO study. Circulation 139(4):431-443

50. Dasgupta NR, Rissing SM, Smith J, Jung J, Benson MD (2020) Inotersen therapy of transthyretin amyloid cardiomyopathy. Amyloid 27(1):52-58

51. Pinto MV, Dyck PJB, Gove LE, McCauley BM, Ackermann EJ, Hughes SG, Waddington-Cruz M, Dyck P (2018) Kind and distribution of cutaneous sensation loss in hereditary transthyretin amyloidosis with polyneuropathy. J Neurol Sci 394:78-83

52. Yamashita T, Ueda M, Misumi Y, Masuda T, Nomura T, Tasaki M, Takamatsu K, Sasada K, Obayashi K, Matsui H (2018) Genetic and clinical characteristics of hereditary transthyretin amyloidosis in endemic and non-endemic areas: experience from a singlereferral center in Japan. J Neurol 265(1):134-140

53. Conceição I, Damy T, Romero M, Galán L, Attarian S, Luigetti M, Sadeh M, Sarafov S, Tournev I, Ueda M (2019) Early diagnosis of ATTR amyloidosis through targeted follow-up of identified carriers of TTR gene mutations. Amyloid 26(1):3-9

54. Monteiro C, Mesgazardeh JS, Anselmo J, Fernandes J, Novais M, Rodrigues C, Brighty GJ, Powers DL, Powers ET, Coelho T (2019) Predictive model of response to tafamidis in hereditary ATTR polyneuropathy. JCI Insight 4(12):e126526

55. Obici L, Kuks JB, Buades J, Adams D, Suhr OB, Coelho T, Kyriakides T (2016) Recommendations for presymptomatic genetic testing and management of individuals at risk for hereditary transthyretin amyloidosis. Curr Opin Neurol 29(Suppl 1):S27

56. Plante-Bordeneuve V (2018) Transthyretin familial amyloid polyneuropathy: an update. J Neurol 265(4):976-983

57. Escolano-Lozano F, Geber C, Barreiros A-P, Birklein F (2020) Follow-up in transthyretin familial amyloid polyneuropathy: useful investigations. J Neurol Sci 413:116776

\section{Affiliations}

\section{Maike F. Dohrn ${ }^{1}$ - Michaela Auer-Grumbach ${ }^{2} \cdot$ Ralf Baron $^{3}$ - Frank Birklein ${ }^{4} \cdot$ Fabiola Escolano-Lozano ${ }^{4}$. Christian Geber $^{5}$. Nicolai Grether ${ }^{6} \cdot$ Tim Hagenacker $^{7} \cdot$ Ernst Hund $^{8,9} \cdot$ Juliane Sachau $^{3} \cdot$ Matthias Schilling $^{10}$. Jens Schmidt ${ }^{11}$. Wilhelm Schulte-Mattler ${ }^{12}$. Claudia Sommer ${ }^{13} \cdot$ Markus Weiler $^{8,9} \cdot$ Gilbert Wunderlich $^{6,14}$. Katrin Hahn ${ }^{15}$}

1 Neuromuscular Outpatient Clinic, Department of Neurology, Medical Faculty, RWTH Aachen University, Aachen, Germany
2 Department of Orthopedics and Trauma Surgery, Medical University of Vienna, Vienna, Austria 
3 Division of Neurological Pain Research and Therapy, Department of Neurology, University Hospital Schleswig-Holstein, Campus Kiel, Kiel, Germany

4 Department of Neurology, University Medical Center of the Johannes Gutenberg University, Mainz, Germany

5 Department of Neurology, Red Cross Pain Centre Mainz, Mainz, Germany

6 Department of Neurology, Faculty of Medicine and University Hospital Cologne, Cologne, Germany

7 Department of Neurology, University Hospital Essen, Essen, Germany

8 Amyloidosis Center Heidelberg, Heidelberg University Hospital, Heidelberg, Germany

9 Department of Neurology, Heidelberg University Hospital, Heidelberg, Germany
10 Department of Neurology with Institute of Translational Neurology, University Hospital of Muenster, Münster, Germany

11 Department of Neurology, University Medical Center Göttingen, Göttingen, Germany

12 Department of Psychiatry and Psychotherapy, University Hospital Regensburg, Regensburg, Germany

13 Department of Neurology, University of Würzburg, Würzburg, Germany

14 Center for Rare Diseases, Faculty of Medicine and University Hospital of Cologne, Cologne, Germany

15 Department of Neurology, Charité University Medicine, Berlin, Germany 